\title{
Cross-species toxicogenomic analyses and phenotypic anchoring in response to groundwater low-level pollution
}

Immacolata Porreca ${ }^{1}$, Fulvio D'Angelo ${ }^{1}$, Daniela Gentilcore ${ }^{1}$, Emanuele Carchia ${ }^{1}$, Angela Amoresano ${ }^{2}$, Andrea Affuso ${ }^{1}$, Michele Ceccarelli,3, Pasquale De Luca', Libera Esposito ${ }^{3}$, Francesco M Guadagno ${ }^{3}$, Massimo Mallardo4, Antonio Nardone ${ }^{5}$, Sergio Maccarone ${ }^{5}$, Francesca Pane ${ }^{2}$, Marzia Scarfò ${ }^{1}$, Paolo Sordino ${ }^{6,7}$, Mario De Felice ${ }^{1,4 \dagger}$ and Concetta Ambrosino ${ }^{1,3^{*}}$

\begin{abstract}
Background: Comparison of toxicogenomic data facilitates the identification of deregulated gene patterns and maximizes health risk prediction in human.

Results: Here, we performed phenotypic anchoring on the effects of acute exposure to low-grade polluted groundwater using mouse and zebrafish. Also, we evaluated two windows of chronic exposure in mouse, starting in utero and at the end of lactation. Bioinformatic analysis of livers microarray data showed that the number of deregulated biofunctions and pathways is higher after acute exposure, compared to the chronic one. It also revealed specific profiles of altered gene expression in all treatments, pointing to stress response/mitochondrial pathways as major players of environmental toxicity. Of note, dysfunction of steroid hormones was also predicted by bioinformatic analysis and verified in both models by traditional approaches, serum estrogens measurement and vitellogenin mRNA determination in mice and zebrafish, respectively.
\end{abstract}

Conclusions: In our report, phenotypic anchoring in two vertebrate model organisms highlights the toxicity of low-grade pollution, with varying susceptibility based on exposure window. The overlay of zebrafish and mice deregulated pathways, more than single genes, is useful in risk identification from chemicals implicated in the observed effects.

Keywords: Microarray, Estrogen, Toxicology, Liver, Toxicogenomics, Low-dose, Chemical mixture, Groundwater pollution, Animal models

\section{Background}

In vitro assays for compound toxicity are commonly based on the assumption that toxicants exposure results in changes in gene expression, a biological phenomenon predictive of successive morphological abnormalities [1-3]. Toxicogenomics, defined as changes in genome function that occur with toxicant interaction [4], is a sensitive, informative and measurable assay to complement traditional toxicological endpoints [5-7]. These advantages prompted

\footnotetext{
*Correspondence: coambros@unisannio.it

${ }^{\dagger}$ Equal contributors

'IRGS, Biogem, Via Camporeale, 83031 Ariano Irpino, Avellino, Italy

${ }^{3}$ Department of Science and Technology, University of Sannio, via Port'Arsa

11, 82100 Benevento, Italy

Full list of author information is available at the end of the article
}

the use of toxicogenomics to test the effect of single molecules or simple chemical mixtures $[8,9]$. The objectives of transcriptomics in environmental studies (ecotoxicogenomics) are the accomplishment of classical toxicological and new molecular endpoints in the identification of exposure-related alterations, and proper consideration of the complex nature of anthropogenic pollution and bioaccumulation events [10-17]. Besides environments are frequently contaminated with multiple classes of compounds, only a limited number of toxicological studies have recently addressed this problem by using omics approaches to fish species, in environmental field [11,18-20].

Ecotoxicogenomics is faced with determination of specific patterns of gene expression elicited by environmental 
samples with known or potential toxicity [12]. Transcriptome analysis has been successfully applied in testing low doses of environmental stressors in biological systems, thus leading to the identification of biomarkers that are easily detectable and related to the observed phenotype, the so called phenotypic anchoring $[21,22]$. In this process, the integration of toxicogenomics data from different models is pivotal to validate deregulated patterns, to challenge the low signal to noise ratio and to predict potential risks for human health [23,24]. Mouse and zebrafish studies indicate that gene expression profile approaches are successful in identifying chemical-specific patterns of altered gene expression [2,25-27]; for this reason, and for their genetics and biology, these models are widely accepted by the scientific community for environmental toxicology studies [10,28].

In populations living near waste dumpsites, the correlation between the exposure to chemical mixtures and health disorders has been monitored with different results [29-32]. Typically, low-level exposure to pollutant mixtures is frequently unappreciated and little is known about the consequences of chronic exposure in infants. Among people exposed to contaminants, infants and foetuses are thought to be more susceptible to insults from toxic chemicals because of the period of rapid development $[33,34]$. This is an important issue since the adverse effects of a long-term corollary of foetal/neonatal exposure to different pollutants can remain undetected till diseases develop in the adulthood. Several studies have investigated the leachate composition [35-37] and related cytotoxicity/mutagenicity in eukaryotic systems, suggesting the potential of leachate to cause harmful effects to public health through seepage into groundwater. Poorly concentrated pollutants remain undetected while they are transformed and enter the food chain. Moreover, their toxicity is underestimated if cocktail effect and bioaccumulation over long-term exposure is not considered.

In the present study, we investigate the effects of exposure to environmental low-level polluted water for distinct exposure time and developmental windows, with a focus on liver toxicity in two model systems, mouse and zebrafish. Methodologically, we correlate microarray data with phenotypic and chemical parameters after short-term exposure of mice and zebrafish, and long-term exposure of mice, to environmental low-grade polluted water. Our findings are a proof that toxicogenomics applied to environmental toxicology studies permits new biomarker identification and risk assessment in the common situation of low-grade pollution and different exposure timing.

\section{Results}

Toxicogenomic evaluation of "acute" exposure in mice To investigate the effects of exposure to environmental polluted waters, samples were collected from dumps located upstream (U) and downstream (D) a sanitary landfill, both insist on the same aquifer. Analyses aimed at the definition of aromatic and heavy metal contents in water samples were carried out by GC-MS and ICP-MS techniques. Additional file 1 reports results representative of different samplings, underlining the similarity between $\mathrm{U}$ and $\mathrm{D}$ waters compared with control water.

The impact of acute exposure to sampled groundwater was investigated by treating 21 PND CD1 mice for 3 months. Outbred CD1 mice were chosen to avoid the influence of genetic background on any phenotypic aspect. During the treatment, no differences were recorded in water/food consumption as well as in mortality and body weight between the two treatment groups compared with control (data not shown).

Since the liver is highly sensitive to toxicant exposure, gene expression profiling analysis of the "acute response" was performed on RNAs obtained from 9 livers/group and using Affymetrix mouse whole genome. Different probe sets were retrieved in U- and D-treated mice, as shown in Volcano Plots and related tables (Additional file 2). The Heatmap and the Venn Diagram highlight many common and unique Differentially Expressed Genes highlight many common and unique Differentially Expressed Genes (DEGs) in $U$ and $D$ group mice (Figure 1A, B). The observation of U- and D-specific DEGs suggests that these waters were similar but not identical (Additional file 1). Common DEGs were further investigated as true markers of groundwater exposure. Using the Ingenuity Pathway Analysis program (IPA, see Materials and Methods section), we identified several biofunctions relevant to the data set, including Hepatic System Disease ( $p$-value $=2,73 \mathrm{E}-03$ ) and Renal and Urological Disease ( $p$-value $=1,37 \mathrm{E}-03)$. The IPA analysis of canonical pathways suggested that transcriptomics-based evidence of alterations in liver activity may be related to perturbation of pathways involved in liver stress responses (Eif2 signalling), or/and to mitochondrial dysfunction (Figure 1C). In the deregulated mitochondrial pathway, we found alteration of several genes involved in the respiratory chain, mostly codifying for components of the NADH:ubiquinone oxidoreductase (complex I, Ndufaf1, Ndufs5, Ndufab1, Ndufb6, Ndufa3). The liver alteration is also supported by toxfunction prediction performed within the IPA analysis (Figure 1D). qRT-PCR analysis of genes related to the two top impinged toxfunctions confirmed microarray data and other IPA tools bioinformatics observations (Figure 1E).

We analysed hepatic and renal activity in acutely treated mice by measuring serum alanine and aspartate transaminases (ALT, AST), alkaline phosphatase (AP), and urea levels. Values of urea, AP and AST were significantly increased in $\mathrm{U}$ and D groups (Figure 2A-C), in agreement with bioinformatics prediction of liver 


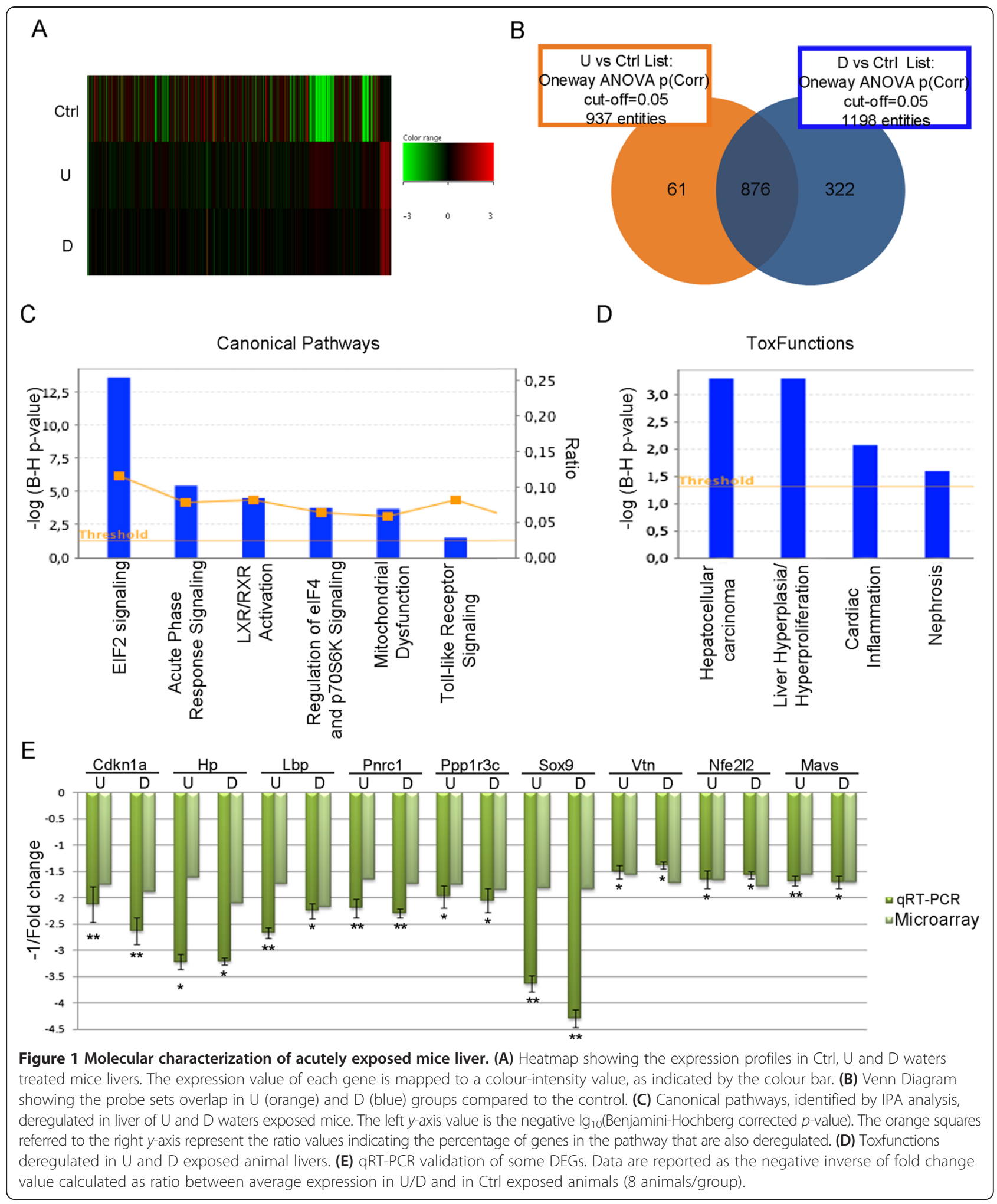

suffering. Conversely, ALT levels were higher only in U animals (Figure 2D). However, hematoxylin/eosin staining of liver sections showed no macroscopic signs of tissue alteration (data not shown).

\section{Comparing mouse and zebrafish transcriptomes}

The identification of deregulated genes in common between mammals and fish may elicit the identification of reliable biomarkers of environmental exposure. Due 

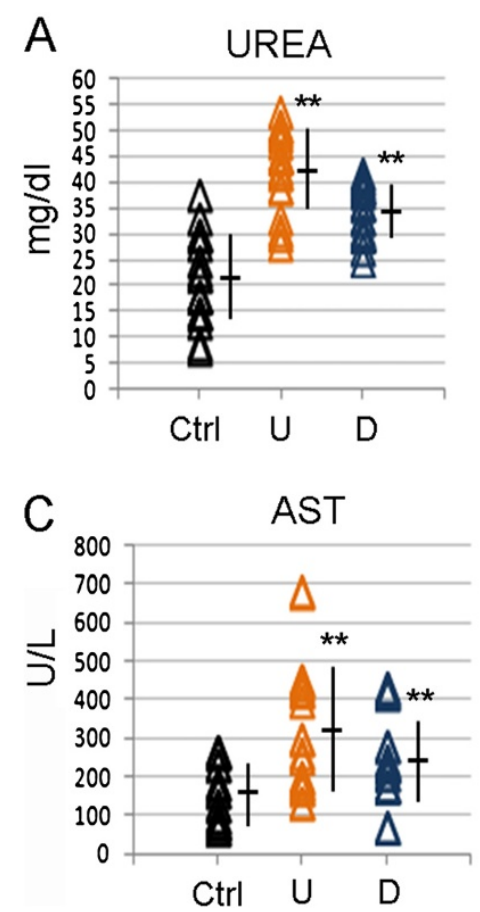
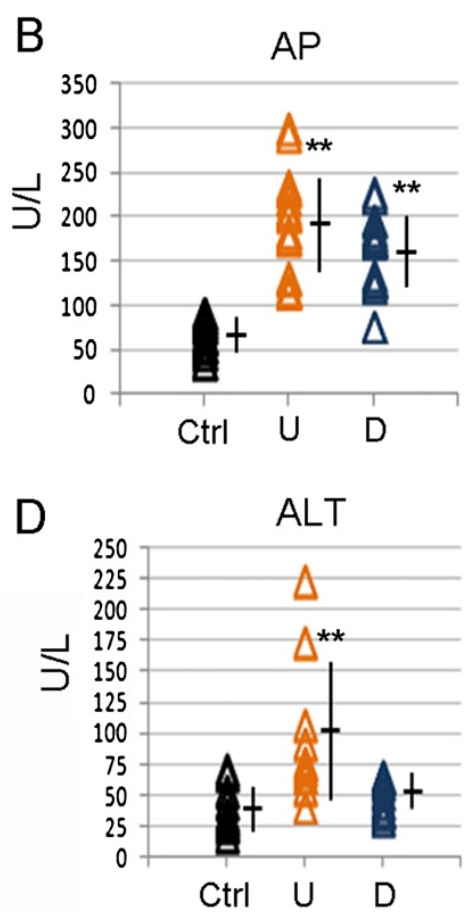

Figure 2 Biochemical analyses in acutely exposed mice. (A) Serum Urea, (B) AP, (C) AST and (D) ALT levels were measured in Ctrl (black), U (orange) and D waters (blue) treated mice (20 animals/group). Each sign is a single mouse. Mean and standard deviation is reported. ${ }^{* *} p$-value $\leq 0,01$.

to zebrafish susceptibility to groundwater treatment, 3 months old fish were enrolled in each treatment group. After 3 months exposure, the treatment was stopped to avoid suffering since animal weight and length were reduced relative to control (Additional file 3).

Transcriptome analysis revealed more changes in gene expression in fish treated with D water (100 genes, 86 down-regulated) than in those exposed to $U$ water $(24,20)$. Almost all U-specific altered probes were included in the $\mathrm{D}$ list (Figure 3A). Volcano plots for these experiments are reported in Additional file 3. Validation by qRT-PCR of two common DEGs is showed in Figure 3B. Gene Ontology analysis has been performed to compare the two acute exposure profilings in mice and zebrafish. 81 gene ontology terms were significantly deregulated in mice with a p-value of 0.05 (Additional file 4). In zebrafish only 3 gene ontology terms were significantly deregulated (Additional file 5). Among them the mitochondrion was shared by the two profilings. Among the 3 genes enrinched in GO mitochondrion term in zebrafish, we validated the reduction of $c t p 2$ transcript, codifying for a protein involved in the $\beta$-oxidation of long-chain fatty acids in the mitochondrial inner membrane. Besides the unchanged expression of respiratory chain genes, lower $c t p 2$ levels can result in a decrease in the production of ATP. Reduced cpt2expression, a PPAR $\alpha$-target gene, was implicated in the development of hepatic steatosis and toxicity in the livers of both zebrafish exposed to the environmental contaminant perfluorononanoic acid and high fat diet-fed mice treated with PCB $15[38,39]$. IPA analysis of common DEGs highlighted steroid hormone biosynthesis among deregulated canonical pathways (Figure 3C) but could not predict any liver function alteration (data not shown).

Comparison of data sets from acutely exposed mouse and zebrafish revealed two molecular responses in common, i.e. the altered activity of steroid hormones synthesis/ signalling biofunctions, and the prediction of aromatase (Cyp19A) as upstream regulator ( $p$-value $=4,95 \mathrm{E}-05$ in mouse, $p$-value $=4,68 \mathrm{E}$-05 in zebrafish), in agreement with the detection of trace chemicals affecting fertility [40]. To verify IPA prediction, estradiol synthesis was examined in both models. Expression of the vitellogenin ( $v t g$ ) gene, typically estrogen-dependent, was reduced in treated zebrafish, in line with estrogen findings. Likewise, plasmatic estradiol levels in acutely exposed mice were in line with IPA-based prediction (Figure 4B). Thus, data suggest that the comparison of toxicogenomics data sets in zebrafish and mouse allows recognition of altered biofunctions.

\section{Toxicogenomic evaluation of chronic exposure started in utero or at 21 PND}

In order to analyse the effects of chronic exposure (12 months) under different exposure windows, mice treatment started at $21 \mathrm{PND}$ or in utero (F1 from four months old exposed CD1 mice) (Figure 5). 


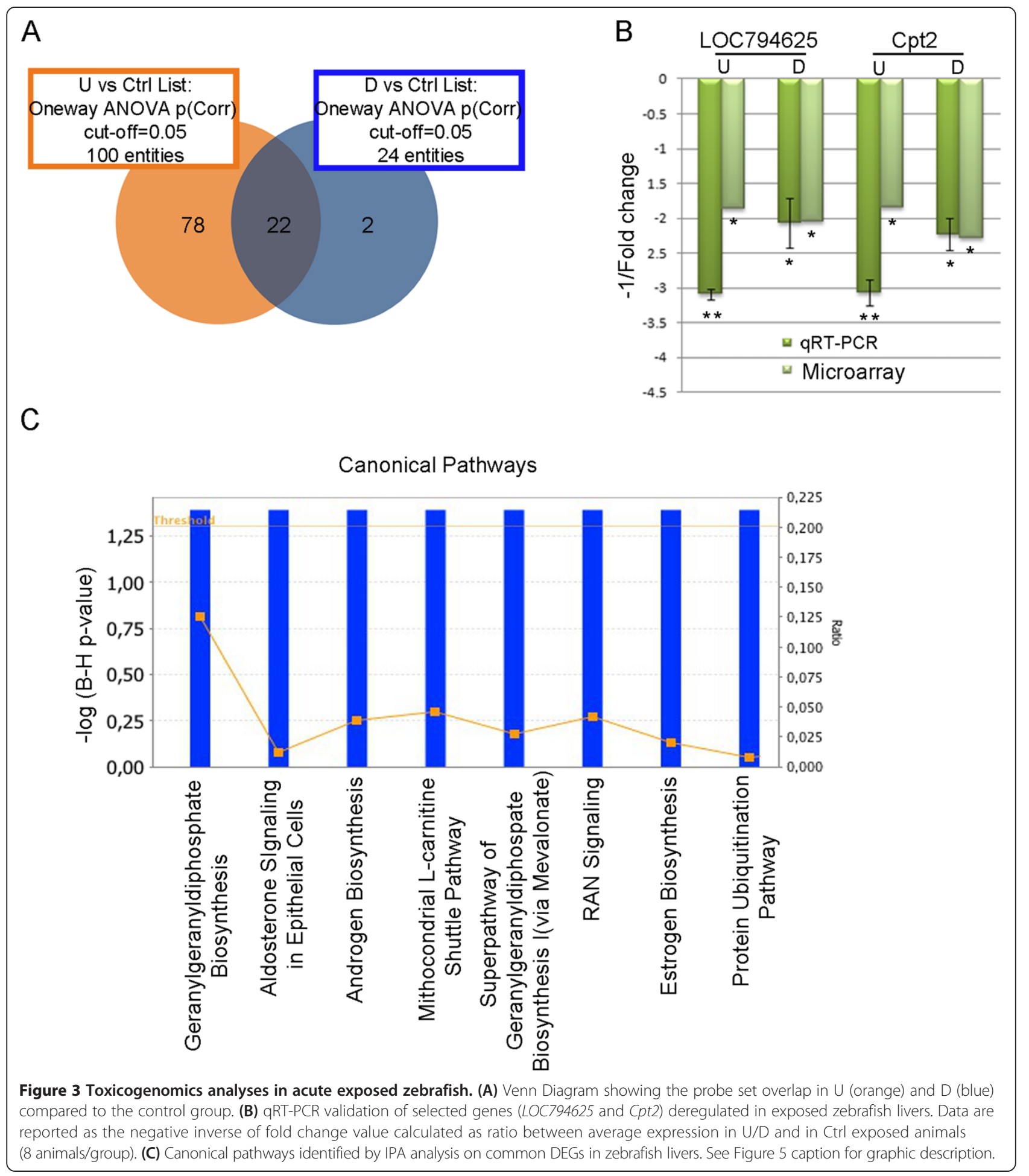

Transcriptome analyses conducted on livers at the end of treatment showed extreme reduction of deregulated probes in chronic exposed parents (P) (Figure 6A) and offspring (F1) (Figure 7A) compared to the acute treatment. This reduction could be interpreted as indication of a compensation effect in chronically exposed mice.
Probe sets deregulated in $\mathrm{P}$ mice watered with $\mathrm{U}$ and D water shared several DEGs (Figure 6A). Furthermore, IPA analysis recognized numerous biofunctions related to impinged liver function (e.g. delay in initiation of liver repair; data not shown). Two canonical pathways, involving the complement system, were significantly 

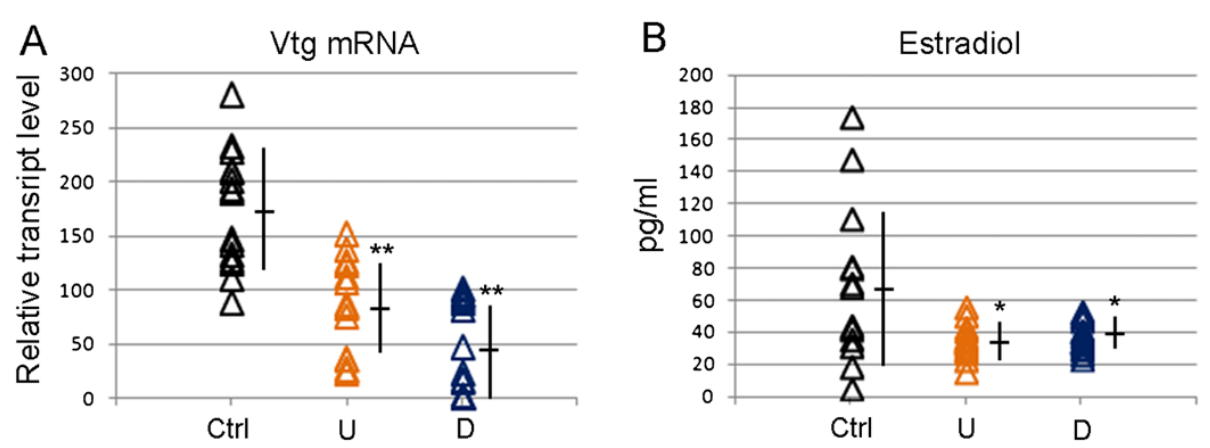

Figure 4 Validation of hormonal alteration in acutely exposed mice and zebrafish. (A) Vtg mRNA level measured by qRT-PCR in liver of zebrafish females (20 animals/group). Each sign is a single animal. (B) Serum estradiol levels measured by ELISA assay in acute exposed mouse females (15 animals/group). Each sign is a single animal. Mean and standard deviation is reported. * $p$-value $\leq 0,05,{ }^{* *} p$-value $\leq 0,01$.

altered (Figure 6B). They were not highlighted by acute exposure data, suggesting the specificity of chronic exposure effects. For this reason, elements of these complement system canonical pathways were used to validate microarray data by qRT-PCR (Additional file 6).

Bioinformatics analysis indicated seleno-methylselenocysteine ( $p$-value $=7.12 \mathrm{E}-04)$ and phenol derivative $(p$-value $=3.44 \mathrm{E}-03)$ as upstream regulators of chemical toxicity. Remarkably, traces of selenium and phenolic compounds were retrieved in the sampled waters (Additional file 1). Analysis by toxfunctions (liver damage, $p$-value $=3.7 \mathrm{E}$-02; liver cholestasis, $p$-value $=3.7 \mathrm{E}-02$; liver necrosis $/$ cell death, $p$-value $=3.7 \mathrm{E}-02)$ evidenced predictable signs of hepatic toxicity (Additional file 6), prompting us to deepen the assessment of liver/renal functionality in P mice by assaying urea, AP, ALT and AST serum levels. We found that levels of urea and AP were significantly increased in the treated mice versus control (Additional file 6). Histopathology evidenced the alteration of hepatic tissue, with the presence of typical signs of microvescicular steatosis in treated mice (Additional file 6).

A high number of U/D-shared deregulated probes was observed also in chronically treated F1animals (Figure 7A).
IPA analysis of common DEGs identified many biofunctions related to cell cycle alteration and cancer (Figure 7B) that were not detected in the $\mathrm{P}$ mice analysis. Thus, they could be considered related to the foetal exposure.

In order to identify exposure-specific signatures, we looked for common DEGs deregulated by $U$ and $D$ treatment in both chronic and acute exposure conditions in mice. Among 30 DEGs common to both data sets, the majority codifies for mitochondrial tRNA (Table 1), in agreement with mitochondrial alteration in liver stressing conditions [41]. 15 out of the 22 mitochondrial tRNAs were strongly up-regulated in both acute and chronic exposure; the reason for their increase is not clear. However it has been reported that hypoxia induces a similar effect in cardiomyocytes [42].

To identify hallmarks of groundwater chronic toxicity, we looked for genes deregulated in both P and F1 upon 12 months treatment. As described in Material and Methods and depicted in Figure 5, P and F1 animals received the same waters for most of the treatment, the only difference being the exposure window. However, only 9 deregulated probes were present in both lists, of which only two DEGs were similarly regulated (Usmg5, Nd6) (Table 2). The reported data suggest that the

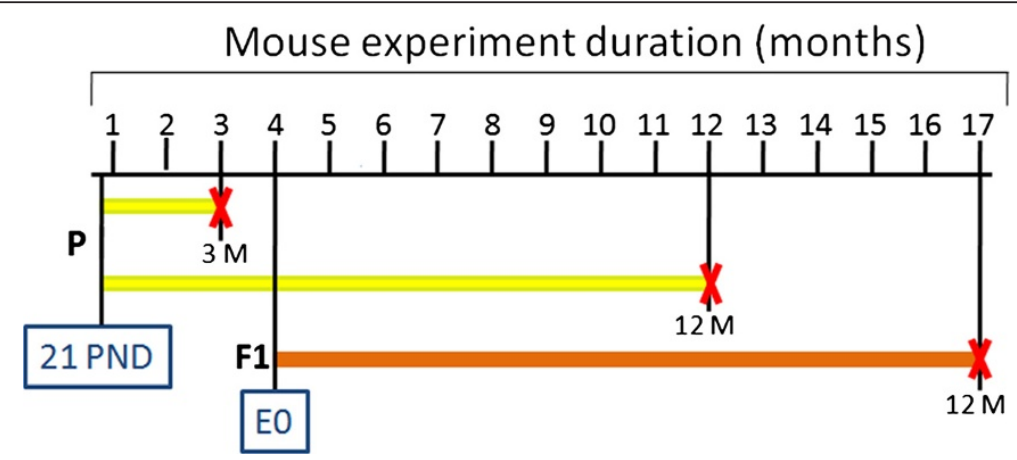

Figure 5 Schematic representation of exposure windows in mice. P generation mice were treated for 3 (acute exposure) and for 12 months (chronic exposure), starting from 21 PND. F1 generation mice, obtained by crossing 4 months old P mice, were treated for 12 months starting from embryonic day 0 . In black horizontal line the experiment duration; in yellow and orange exposure duration for P and F1, respectively; the red crosses indicate the end of the treatment. 


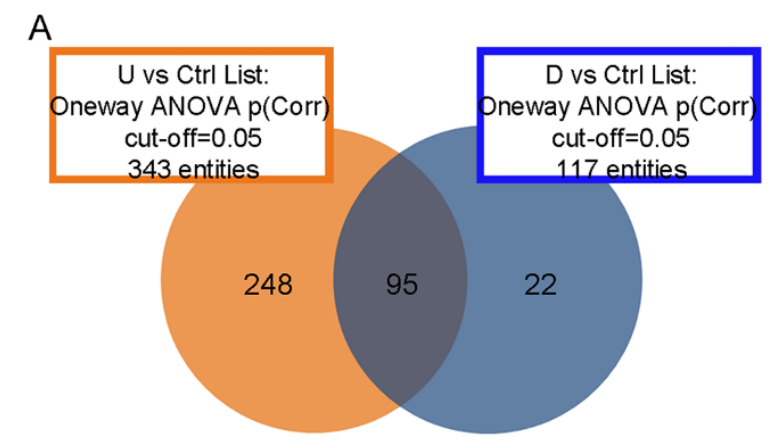

B

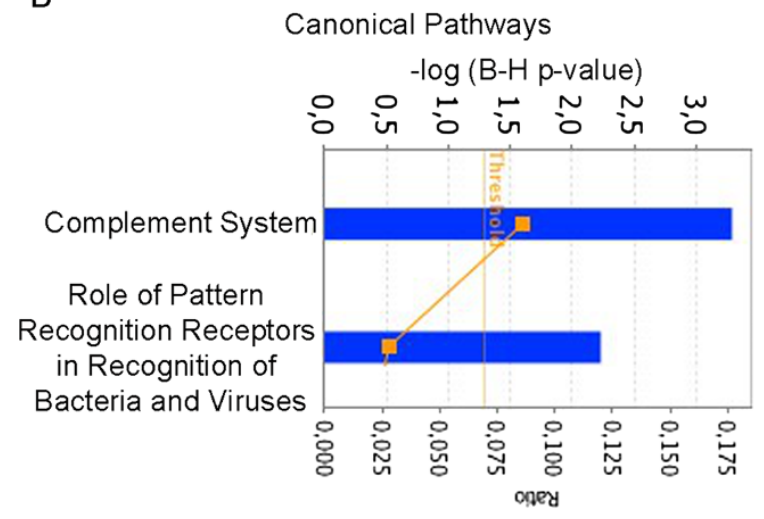

Figure 6 Transcriptomics analyses in livers of 12 months $P$ exposed mice. (A) Venn Diagram showing probe set overlap between $U$ (orange) and D (blue) compared to the control group after 12 months of treatment started at PND 21. (B) Canonical pathways deregulated in liver of exposed P mice. See Figure 5 caption for graphic description.

effects of acute $v s$ chronic exposures as well as the effects of chronic exposure windows were mainly specific, likely as a consequence of adaptive response.

\section{Discussion}

Toxicogenomics aims to identify genes whose altered expression is associated to observed phenotypes or unpredicted outcomes. Matching high-throughput transcriptional approaches to traditional toxicological criteria is considered a powerful method for testing the impact of low-dose pollutant mixtures, particularly in natural settings. Here, we evaluated low-level contaminated groundwater toxicity by both approaches in vertebrate mouse and zebrafish. Determination of polluted groundwater toxicity in the experimentally controlled animal facility reduces disturbing factors encountered with environmental sampling of wild organisms.

Bioinformatics analyses of liver transcriptomics profiles in the acute exposure treatments revealed the effect of pollutants, whose presence in groundwater was supported by chemical testing (e.g. dibutyl phthalate, $p$-value $=$ 1.46E-4) (Additional file 1). The alteration of pathways involved in stress response (EIF2-, eIF4-, p70S6K- signalling pathways) suggested their relevance in the evaluation of environmental exposure. Phenotypic and molecular data obtained in the analysis of acutely exposed mice point at liver toxicity, and advise a particular role for the stress response and mitochondria related pathways in its development. Indeed, the IPA analysis on acutely treated mice highlighted, among the canonical pathways, the mitochondrial dysfunction including genes for the mitochondrial respiratory chain (Ndufaf1, Cox6b10, Ndufs5, Cox6a1, Uqcr11, Ndufab1, Ndufb6, Ndufa3). All of them are nuclear genes down-regulated in the liver of acutely exposed mice. This condition could lead to the impairment in the electron transport and ATP synthesis and, overall, could compromise the health of liver cells. Inhibition of the respiratory and impairment of complexes I as well as of mitochondrial $\beta$-oxidation has been frequently associated to acute exposure to drugs and hepatocytes toxicity [43]. Furthermore, down-regulation of electron transport complex genes as well as mitochondrial alterations has been associated with several diseases, being chronic liver disease among them [44-49].

Among the genes whose expression level was altered in the acutely exposed mice, we found downregulation of Cdkn1a and Nfe2l2. Cdkn1a is the gene codifying for p21, which is a p53-dependent key regulator of cell fate, as it triggers cell cycle arrest in the G1 phase under various stress conditions [50]. It has been recently suggested that reduced p21 expression can support liver fibrosis through reduced hepatic stellate cells senescence [51]. It is relevant to note that in our experimental condition, hepatic stellate cells activation was one of the disturbed canonical pathways ( $p$-value $=4,3 \mathrm{E}-001)$. As stated in the Results section, $\mathrm{Nfe} 2 \mathrm{l} 2$ is one of the few genes deregulated also in the chronic exposed mice (Table 1), where we found evidence of micro-vescicular steatosis (Additional file 6). The transcription factor $\mathrm{Nfe} 2 \mathrm{l} 2$ plays a protective role in hepatic cells as a key regulator for induction of detoxifying enzymes, antioxidative stress genes and several other enzymes involved in cellular protection. Its deficiency leads to exacerbation of chemical hepatotoxicity and to a considerable increase in micro and macrovescicular steatosis [52].

Indeed, chronically exposed mice showed progressive alteration of liver parenchyma and increased level of alkaline phosphatase, as reported in human non-alcoholic steatohepatitis where it often evolves in hepatocellular carcinoma, a disease pathway whose alteration was seen in the present research. A compensation effect was evidenced at molecular level by the reduction of DEGs. Sets of deregulated biofunctions were almost overlapping in acute and chronic exposure (data not shown). One exception was the specific alteration of the complement system. C1qa, c1qb and c1qc are members of the complement cascade, a fundamental component in the innate immunity helping in the clearance of pathogens. Recent studies 


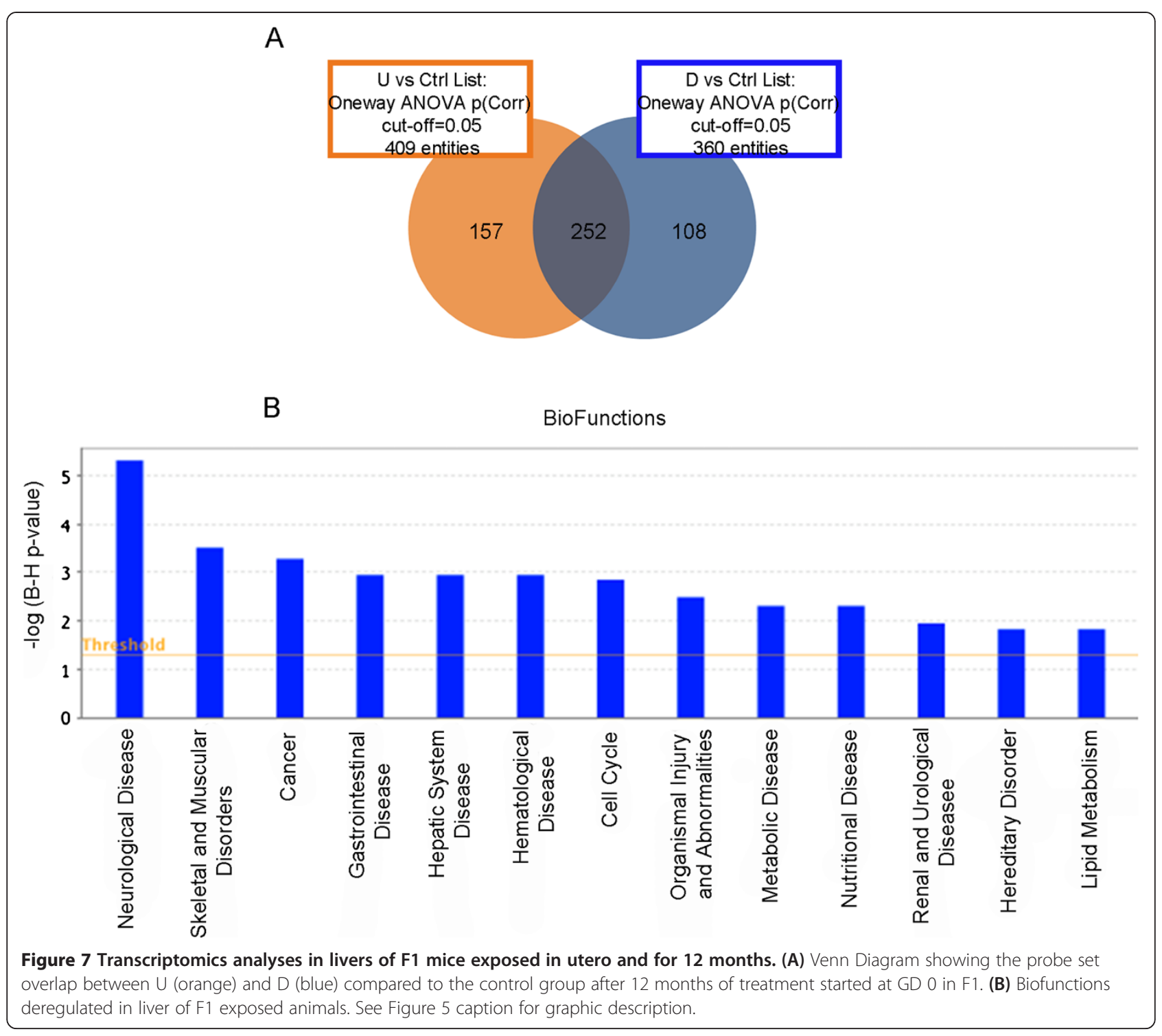

demonstrated that complement activation may contribute to cancer growth by facilitating the dysregulation of mitogenic signaling pathways [53]. The three complement system genes were up-regulated in the liver of chronically exposed mice; in particular, overexpression of $\mathrm{C} 1 q$ complement system components may be envisaged as indicative of hetapotoxicity since its transcription in liver hematopoietic cells was induced in several types of damage [54,55].

The possibility that exposure during foetal life could be more harmful than in the adulthood has been explored $[33,34,56]$. Here, our results confirm the selective impact of the exposure window in DEG changes, as only few genes (Usmg5 and Nd6) were shared among parents and offspring. Usmg5 was first recognized as a gene whose mRNA level increased during skeletal muscle growth in rats [57]. USMG5 protein was shown to be associated with ATP synthase in the mitochondria [58] and to contribute to the maintenance of ATP synthase population, an indication of its importance in cellular energy metabolism [59]. ND6 is one of the 7 mitochondrial DNA (mtDNA) encoded subunits of respiratory Complex I, again suggesting the alteration of mitochondria biology in the exposed animals also in chronic exposure conditions.

DEGs involved in cancer development (cell cycle and DNA repair) were specifically observed in offspring. Even if cancers were not observed in the collected organs, genotype context or longer exposure time could play a major role in their development. The identified genes could represent a predictive biomarker of exposure and effects whose identification is pivotal in monitoring. Interestingly, increased incidence of cancers has been reported in people leaving in landfill areas, where they are 
Table 1 Genes deregulated in livers of both 3 and 12 months mice exposed to $U$ and $D$ waters

\begin{tabular}{|c|c|c|c|c|c|c|}
\hline \multirow{3}{*}{$\begin{array}{l}\text { Transcripts } \\
\text { Cluster Id }\end{array}$} & \multirow[t]{3}{*}{ Gene name } & \multirow[t]{3}{*}{ Gene description } & \multicolumn{4}{|c|}{ Fold change } \\
\hline & & & \multicolumn{2}{|c|}{3 months } & \multicolumn{2}{|c|}{12 months } \\
\hline & & & U vs Ctrl & D vs Ctrl & U vs Ctrl & D vs Ctrl \\
\hline 10603833 & Usmg5 & Upregulated during skeletal muscle growth 5 & -4.53 & -4.28 & -2.83 & -2.95 \\
\hline 10374476 & Rps17 & Ribosomal protein S17 & -2.96 & -3.19 & -1.85 & -1.89 \\
\hline 10357242 & Dbi & Diazepam binding inhibitor & -2.87 & -2.71 & -1.84 & -2.23 \\
\hline 10387816 & Rnasek & Ribonuclease, RNase K & -2.17 & -2.33 & -1.61 & -1.78 \\
\hline 10344817 & Cspp1 & Centrosome and spindle pole associated protein 1 & -1.75 & -1.62 & -1.80 & -2.38 \\
\hline 10483809 & $\mathrm{Nfe} 2 \mathrm{l} 2$ & Nuclear factor, erythroid derived 2, like 2 & -1.66 & -1.78 & -1.71 & -1.81 \\
\hline 10500798 & & & -1.57 & -1.78 & -2.75 & -2.78 \\
\hline 10598089 & mt-Te & tRNA glutamic acid, mitochondrial & 2.12 & 2.47 & 4.20 & 5.01 \\
\hline 10598087 & ND6 & NADH dehydrogenase subunit 6 & 2.82 & 3.37 & 1.86 & 3.73 \\
\hline 10598073 & $\mathrm{mt}-\mathrm{Tq}$ & tRNA glutamine, mitochondrial & 4.07 & 5.85 & 5.67 & 7.28 \\
\hline 10528191 & Speer4d|Speer4c|Speer4e| & $\begin{array}{l}\text { Spermatogenesis associated glutamate (E)-rich } \\
\text { protein } 4 \mathrm{~d} / 4 \mathrm{c} / 4 \mathrm{e}\end{array}$ & 4.13 & 4.67 & 1.65 & 1.80 \\
\hline 10598083 & $\mathrm{mt}-\mathrm{Ts} 1$ & tRNA serine 1, mitochondrial & 5.32 & 6.71 & 3.00 & 4.83 \\
\hline 10598091 & $m t-T p$ & tRNA proline, mitochondrial & 5.62 & 7.62 & 3.11 & 3.85 \\
\hline 10598075 & mt-Ta & tRNA alanine, mitochondrial & 5.93 & 7.82 & 16.92 & 26.75 \\
\hline 10598023 & $m t-T v$ & tRNA valine, mitochondrial & 6.17 & 6.69 & 4.21 & 5.75 \\
\hline 10519811 & Speer8-ps1|Speer7-ps1 & $\begin{array}{l}\text { Spermatogenesis associated glutamate (E)-rich } \\
\text { protein } 7 / 8, \text { pseudogene } 1\end{array}$ & 6.34 & 6.92 & 3.13 & 3.88 \\
\hline 10598057 & $\mathrm{mt}-\mathrm{Tr}$ & tRNA arginine, mitochondrial & 6.40 & 7.63 & 10.12 & 28.13 \\
\hline 10436773 & Gm7735|Gm9789 & & 6.48 & 6.90 & 3.75 & 3.25 \\
\hline 10412517 & Gm3002|Gm10021|Gm3512 & & 7.66 & 10.80 & 3.88 & 4.55 \\
\hline 10582888 & & & 7.70 & 9.65 & 2.83 & 5.64 \\
\hline 10598081 & mt-Ty & tRNA tyrosine, mitochondrial & 10.46 & 13.91 & 6.51 & 10.49 \\
\hline 10598079 & $\mathrm{mt}-\mathrm{Tc}$ & tRNA cysteine, mitochondrial & 10.88 & 15.64 & 4.72 & 7.30 \\
\hline 10598018 & mt-Tf & tRNA phenylalanine, mitochondrial & 11.56 & 14.23 & 14.71 & 27.37 \\
\hline 10598062 & mt-Th & tRNA histidine, mitochondrial & 13.20 & 15.78 & 27.68 & 46.30 \\
\hline 10598077 & $m t-T n$ & tRNA asparagine, mitochondrial & 21.72 & 32.04 & 6.55 & 9.85 \\
\hline 10598041 & $m t-T k$ & tRNA lysine, mitochondrial & 24.14 & 28.86 & 39.43 & 66.79 \\
\hline 10598071 & $m t-T t$ & tRNA threonine, mitochondrial & 27.51 & 35.77 & 7.81 & 15.37 \\
\hline 10598064 & $\mathrm{mt}-\mathrm{Tl} 2$ & tRNA leucine 2, mitochondrial & 58.00 & 70.56 & 44.83 & 70.91 \\
\hline 10353034 & Snord87 & Small nucleolar RNA, C/D box 87 & -3.20 & -3.39 & 2.83 & 2.77 \\
\hline 10398451 & Rps25|Gm4963 & Ribosomal protein S25 | predicted gene 4963 & -1.70 & -1.81 & 1.75 & 1.80 \\
\hline 10465831 & 5730408K05Rik & RIKEN cDNA 5730408 K05 gene & -2.26 & -2.30 & 4.41 & 4.10 \\
\hline
\end{tabular}

In bold, genes inversely deregulated in the two data sets. mt- stays for mitochondrial.

The arithmetic fold change is reported.

potentially exposed to polluted groundwater used for agriculture or other human activities. Further work is necessary to explore this hypothesis.

In toxicogenomics, studies of gene expression alteration in phylogenetically distant species are supposed to assist in the identification of altered pathways that impinge on human health. To this aim, we investigated the effects of polluted groundwater exposure on mice and zebrafish liver by toxicogenomics. Even if no common
DEGs were retrieved in both vertebrates, bioinformatics analysis and phenotypic assays indicate aromatase and estrogen biosynthesis changes. These findings agreed with the suggestion that functional pathways could be better and reliable markers than single genes. This observation is consistent with the documented effect of several water pollutants (metals, plasticizers and others) on hormonal axes linked to reproductive health outcomes [60-64], as seen also in our experimental settings 
Table 2 Genes deregulated in chronic exposure liver tissue of $U$ and $D$ treated mice in both P and F1

\begin{tabular}{|c|c|c|c|c|c|c|}
\hline \multirow{3}{*}{$\begin{array}{l}\text { Transcripts } \\
\text { Cluster Id }\end{array}$} & \multirow[t]{3}{*}{ Gene name } & \multirow[t]{3}{*}{ Gene description } & \multicolumn{4}{|c|}{ Fold change } \\
\hline & & & \multicolumn{2}{|c|}{$\mathbf{P}$} & \multicolumn{2}{|c|}{ F1 } \\
\hline & & & U vs Ctrl & D vs Ctrl & U vs Ctrl & D vs Ctrl \\
\hline 10572813 & Usmg5 & Upregulated during skeletal muscle growth 5 & -2.89 & -3.19 & -1.54 & -1.66 \\
\hline 10598062 & NC_005089* & & 27.68 & 46.30 & 5.28 & 3.63 \\
\hline 10598064 & NC_005089* & & 44.83 & 70.91 & 3.40 & 2.29 \\
\hline 10598087 & ND6 & NADH dehydrogenase subunit 6 & 1.86 & 3.73 & 3.76 & 4.43 \\
\hline 10448182 & Mir703 & microRNA 703 & 1.61 & 1.64 & -1.74 & -1.73 \\
\hline 10507870 & & & 3.51 & 3.20 & -1.76 & -1.94 \\
\hline 10507872 & & & 3.59 & 3.32 & -1.86 & -2.16 \\
\hline 10512487 & Rmrp & RNA component of mitochondrial RNAase P & 2.49 & 2.66 & -2.10 & -2.30 \\
\hline 10516908 & Snora73a & & 4.51 & 4.26 & -2.36 & -2.49 \\
\hline
\end{tabular}

*Mitochondrial genome.

In bold, genes inversely deregulated in the two data sets parents (P) and offspring (F1).

The arithmetic fold change is reported.

(manuscript in preparation). Here, toxicogenomics showed its predictive strength in identifying biomarkers, steroid hormones, that can be easily detected in blood, suitable for monitoring the impact of anthropogenic activities on human and identifying risks for human populations even if not indicative of specific pollutants.

In all treatment conditions, observed phenotypic effects can correlate to alterations in the stress response pathways and, mainly, in mitochondria activities, as supported by the ability of leachates to induce oxidative stress in organs $[65,66]$. These pathways could be effectors of low-dose mixture toxicity, playing a role in the alteration of liver function and in the regulation of hormones biosynthesis, as previously shown [14].

\section{Conclusions}

The reported data suggest that toxicogenomics analyses of different animal models and exposure conditions (timing and window) have the potential to disclose unpredicted outcomes and, most importantly, pathways useful for human and environmental health risk assessment also in conditions of low-level exposure. Our study points to the importance of considering pathways more than single gene alteration in toxicological assessment. It also allows the identification of specific pathways, with mitochondria as key factors of toxicity response, and sexual hormones as biomarker in environmental assessment.

\section{Methods}

\section{Geochemical analyses}

Water sampling was performed in a landfill located in southern Italy (Lat $41^{\circ} 12^{\prime} 23,54^{\prime}$ ' $\mathrm{N}$; Long $15^{\circ} 12^{\prime} 27,63^{\prime}$ ' $\mathrm{E}$, datum WGS84), with the permission of the municipal local authority. The present study did not involve endangered or protected species.
Water samples were collected from five 15 meters deep piezometers that are located in the saturated portion of an aquifer consisting of poorly permeable lithologies. Piezometers are situated transverse to the axis of groundwater flow: two upstream and three downstream the landfill (referring to the water flow direction). The sampling occurred every 15 days under dynamic conditions by means of a micro pump.

Aliquots of water solution $(1 \mathrm{ml})$ from each sample were directly analysed by Inductively Coupled Plasma Mass Spectometry (ICP-MS) with an Agilent 7700 ICP-MS (Agilent Technologies), as described in detail in Additional file 1. Upon liquid-liquid extraction with chloroform, hexane and dichloromethane (1:1 v/v, performed 3 times), organic substances were collected, dried and dissolved in $200 \mu \mathrm{l}$ of hexane, before GC-MS analysis performed on a 5390 MSD quadrupole mass spectrometer (Agilent Technologies), as detailed in Additional file 7.

\section{Animals and treatments}

Groundwater used for animal treatment was filtered through glass and $0.22 \mu \mathrm{m}$ (Millipore) filters and stored at $4^{\circ} \mathrm{C}$.

Animal experiments were performed in compliance with the European Council Directive 86/609/EEC and the Italian Legislation on Animal Experimentation (D.Lvo 116/92) and procedures were approved (ID number 21-2009) by the Ethical committee named CESA (Committee for the Ethics of the Experimentations on Animals) of the Biogem Institute of Genetics Research "Gaetano Salvatore" (IRGS). The project has been communicated to the employed office of the Ministry of Health following the rules of the D.Lvo 116/92.

Mice were kept under standard facility conditions $\left(22 \pm 2^{\circ} \mathrm{C}, 55+10 \%\right.$ humidity, $12: 12 \mathrm{~h}$ light-dark cycle) 
in a specific pathogen-free facility. Animals received water and standard diet (4RF21 form Mucedola) "ad libitum"; type II EU cages, in polysulfone, had space to allow motility and parental care. Mice were sacrificed by carbon dioxide inhalation.

Fifty 21 Post Natal Days (PND) CD1 mice (outbred, 30 male and 30 female) were randomly recruited for each of the three F0 treatment groups that received drinking tap-water (control, Ctrl), waters sampled from dumps upstream (U) or downstream (D) the landfill. Sampling from two different locations around the landfill area were undertaken to perform a robust toxicogenomic analyses, based on different (up and down) data sets whose shared elements were used for bioinformatics analyses. We chose this approach in order to eliminate from the analyses genes whose deregulation could be related to other reasons (noise). After 3 months of treatment (acute exposure, $\mathrm{P}$ generation), twenty mice/group were sacrificed, blood and several organs collected. Remaining animals were mated for F1 generation and continuously treated till sacrifice (12 months, chronic exposure, $\mathrm{P}$ generation) for blood and organ sampling. Thirty F1 mice per group were treated for 12 months before sacrifice. Schematic representation of the mice study design is depicted in Figure 5.

Fish were maintained in $50 \mathrm{l}$ sterile glass tanks with 20 animals each, under standard laboratory conditions $\left(28 \pm 0.5^{\circ} \mathrm{C}, 14: 10 \mathrm{~h}\right.$ light: dark cycle). The water was continuously aerated, filtered and $1 / 3$ of its volume was manually renewed every three days. Ammonia, nitrate, nitrite, $\mathrm{pH}$ and water hardness was monitored twice a week using commercial kit (Tetra $\mathrm{GmbH}$ ). Fish were daily fed freshly hatched Artemia nauplii once and granular food (Special Diets Services) twice. Sixty 3 months old zebrafish (AB strain, 30 males and 30 females) were randomly recruited from each Ctrl, U and D treatment group, distributed in three replicate tanks for condition. After 3 months treatment, fish were sacrificed by overdose of tricaine methane sulfonate (MS222, 200-300 mg/l) by prolonged immersion and their lengths and weight recorded before organ dissection.

\section{Hormone measurements}

Serum prepared from collected blood samples was $-80^{\circ} \mathrm{C}$ frozen until assayed by Estradiol EIA kit (Cayman) following manufacturer's instructions. Each sample was analyzed in triplicates. $p$-value was calculated by $t$-student test.

\section{RNA extraction and real-time RT-PCR}

RNA was isolated from mouse and zebrafish liver tissues using Trizol reagent (Invitrogen) and purified by RNeasy mini kit (Qiagen). cDNA synthesis and qRT-PCR analysis were set for 8 animals, each carried out in triplicate as previously reported [40]. Data obtained were normalized on the relative expression of reference gene Tubulin in mouse and $r p l 13 a$ in zebrafish and reported as ratio between $\mathrm{U}$ or $\mathrm{D}$ vs Ctrl expression values. Primer sequences are reported in Table 3. $p$-value was calculated by $t$-student test.

\section{Microarray and bioinformatic analysis}

Hepatic RNA for microarray was extracted and cleaned as reported above. Nine animals per group were randomly divided into three equivalent sets, and a constant amount of RNA from animals in the same set was pooled into one single sample in order to eliminate individual differences

Table 3 Genes analysed by qRT-PCR

\begin{tabular}{|c|c|c|c|}
\hline Gene name & Gene description & Forward primer $5^{\prime}-3^{\prime}$ & Reverse primer $5^{\prime}-3^{\prime}$ \\
\hline Cdkn1a & Cyclin-dependent kinase inhibitor 1A (P21) & atccagacattcagagccacag & acgaagtcaaagttccaccgt \\
\hline $\mathrm{Hp}$ & Haptoglobin & cttccagagagaggcaagaga & gcccaactccacagcaaaaag \\
\hline $\mathrm{Lbp}$ & Lipopolysaccharide binding protein & gcatccagacaaggcacaag & cgaggtcgtggagctgaata \\
\hline Pnrc1 & Proline-rich nuclear receptor coactivator 1 & ccacagacagcccccactc & tgtataccatgcacaagctggc \\
\hline Ppp1r3c & Protein phosphatase 1 , regulatory (inhibitor) subunit $3 C$ & caatgagctgcaccagaatga & gtggtgaatgagccaagcaa \\
\hline Sox9 & SRY-box containing gene 9 & tctggaggctgctgaacgag & gettgtccgttcttcaccga \\
\hline Vtn & Vitronectin & agtgcaagccccaagtaacg & ccgtccgtccgaggatttag \\
\hline $\mathrm{Nfe} 2 \mathrm{I} 2$ & Nuclear factor, erythroid derived 2, like 2 & gcatgatggacttggagttgc & gctcatagtccttctgtcgct \\
\hline Mavs & Mitochondrial antiviral signaling protein & tatccgagacaaccacagcaa & gtcgatcaagatgactgggtg \\
\hline C1qa & Complement component 1, q subcomponent, alpha polypeptide & tgtcccaccatcagcaaagg & gtctccatggtgtccctgc \\
\hline$C 1 q b$ & Complement component 1, q subcomponent, beta polypeptide & gacccagacttccgetttct & ctcaccccactgtgtcttca \\
\hline $\mathrm{C} 1 \mathrm{qc}$ & Complement component 1, q subcomponent, C chain & accctcaggatggtcgttgg & tgagtggtagggccagaaga \\
\hline Tub-a & Tubulin-a & caacaccttcttcagtgagacagg & tacatgatctccttgccaatggt \\
\hline LOC794625 & Up-regulated during skeletal muscle growth protein 5 & gggcaccagtttgcttgattg & cctcctgccagtgattgtgt \\
\hline Cpt2 & Carnitine palmitoyltransferase ॥ & aaccgctggtacgacaa & ggacgcaggctgagaac \\
\hline Rpl13a & Ribosomal protein L13A & tctggaggactgtaagaggtatgc & agacgcacaatcttgagagcag \\
\hline
\end{tabular}


within group. Three arrays were used for each group. cRNA was generated by using the Affymetrix One-Cycle Target Labeling and Control Reagent kit (AffymetrixInc), following the manufacturer's protocol, starting from $5 \mu \mathrm{g}$ of total RNA. Biotinylated cRNA was hybridized to the GeneChip Mouse Gene 1.0 ST Array [(MoGene-1_0-st-v1, Affymetrix) and to GeneChip Zebrafish Gene 1.0 ST Arrays (Affymetrix). Chips were washed and scanned on the Affymetrix Complete GeneChip System, generating digitized image data (DAT) files.

The datasets obtained were analyzed with GeneSpring GX 12 Software (Agilent Technologies). Robust multichip average (RMA) algorithm $[67,68]$ was used for summarization and normalization. Hybridization quality was assessed by spiked-in controls. Principal Component Analysis (PCA) was performed to check data quality that resulted adequate for all samples. Transcripts were filtered by their signal intensity values, selecting transcripts with intensity values between 20 and 100 percentile in at least 1 out of each set samples for differential analysis.

Differentially expressed transcripts between exposed livers vs controls were filtered for absolute fold change $\geq$ 1.5 and corrected $p$-value $\leq 0.05$. Statistical analysis was performed using Oneway ANOVA adjusted for multiple comparison by the Benjamini-Hochberg method.

Functional annotation for differentially expressed transcripts was performed using Ingenuity Pathway Analysis (IPA; http://www.ingenuity.com), a web-based tool for the identification of biological functions, canonical pathways, transcription factors as well as toxofunctions that are most significant to the dataset. Fisher Exact test was used to calculate the $p$-value determining the likelihood that the association between the set of focus genes in the dataset and a given process or pathway is due to chance alone. Corrected $p$-value calculation (based on the Benjamini-Hochberg method) controlled the error rate in analysis results and focus in on the most significant biological functions associated with DEG. Gene ontology (GO) analysis was performed using David software (http://david.abcc.ncifcrf.gov) $[69,70]$. The listed GO terms included three or more DEGs $p$-value $<0.05$.

\section{Availability of supporting data}

Microarray data are available in the ArrayExpress database (www.ebi.ac.uk/arrayexpress) under accession numbers E-MTAB-2905 (for mouse arrays) and E-MTAB-2906 (for zebrafish arrays).

\section{Additional files}

Additional file 1: Chemical analysis of Ctrl, $\mathrm{U}$ and $\mathrm{D}$ waters.

Additional file 2: Transcriptomic analyses in liver of acutely exposed mice. Volcano plots of microarray data in $U(A)$ and $D(B)$ compared to $\mathrm{Ctrl}$ treated animals. The $y$-axis value is the negative logarithm base 10 of the corrected $p$-value. A green horizontal line on the plot represents the user-defined significant threshold for $p$-value. The $x$-axis is shown as the logarithm base 2 of the fold change in expression level between treated and control livers. The vertical green lines on the plot represent the user-defined thresholds for fold change. Red dots are up-regulated probes, green dots down-regulated probes. The number of down/up-regulated probes for each Volcano plot is reported in the underlying table.

Additional file 3: Zebrafish phenotypic and molecular changes induced by groundwater treatment. (A) Body weight and (B) body length of adult zebrafish exposed for 3 months to Ctrl, $U$ or D waters. Data are reported separately for female and male fish and, for each point, 20 animals were recorded. Volcano plots of microarray data in $U(C)$ and D (D) compared to Ctrl treated animals. For plot description see the caption to the Additional file 1. The number of down/up-regulated probes for each Volcano plot is reported in the underlying table.

Additional file 4: Gene Ontology analysis of DEGs in acutely exposed mice.

Additional file 5: Gene Ontology analysis of DEGs in acutely exposed zebrafish.

Additional file 6: Liver molecular and phenotypic characterization of chronic exposed mice. (A) qRT-PCR validation of selected genes (C1qa, C1qb, C1qc) deregulated in chronically exposed livers. Data are reported as fold change value calculated as ratio between average expression in U/D and in Ctrl exposed animals. 8 animals were analysed for each group. (B) Toxfunctions deregulated in $U$ and D chronically exposed animal livers. Serum Urea (C), AP (D), AST (E) and ALT (F) levels measured in mice treated with Ctrl (black), U (orange) or D (blue). The analysis was conducted on 20 animals per treatment groups. Each sign is a single mouse. For each treatment group mean and standard deviation is reported. $(G)$ Haematoxylin/ eosin staining of liver sections of $\mathrm{Ctrl}, \mathrm{U}$ and $\mathrm{D}$ chronically exposed mice. ${ }^{*} p$-value $\leq 0,05,{ }^{* *} p$-value $\leq 0,01$.

Additional file 7: Material and methods.

\section{Abbreviations}

U: Upstream water; D: Downstream water; qRT-PCR: Quantitative real time PCR; DEGs: Deregulated expressed genes; P: Parents; F1: Offspring; IPA: Ingenuity pathway analysis.

\section{Competing interests}

The authors have declared that they have no competing interests.

\section{Authors' contributions}

PS, MDF, MM and CA conceived and designed the experiments. IP, DG and EC carried out organ sampling, molecular and histological analysis. IP performed the fish exposure and organ sampling, and drafted the manuscript. An Am and FP performed the water analysis. An Af and MS participated in the mouse exposure. LE and FMG carried out the geochemical evaluation of the area. AN and SM performed the water sampling. PDL performed the microarray experiments. FDA and MC performed the bioinformatics analysis. PS, MDF, CA, MM and FMG provided reagents. CA, PS and MM prepared the final version of the manuscript. All authors read and approved the final manuscript.

\section{Acknowledgements}

We thank G. Mercadante and animal facility personnel for technical support. Finally we thank IRGS, Biogem for the support. We thank Dr. Rachele Zair for the careful reading and editing of the manuscript. This work was funded by Italian Workers' Compensation Authority grant (E95E10000510005) and by IRGS Biogem Institute. PS was funded by MIUR (PONa3_0239 and FIRB RBFR12QW4I). The funders had no role in study design, data collection and analysis, decision to publish, or preparation of the manuscript.

\section{Author details}

${ }^{1}$ IRGS, Biogem, Via Camporeale, 83031 Ariano Irpino, Avellino, Italy.

${ }^{2}$ Department of Chemical Sciences, University of Naples Federico II, Via Cinthia, 80126 Naples, Italy. ${ }^{3}$ Department of Science and Technology, University of Sannio, via Port'Arsa 11, 82100 Benevento, Italy. ${ }^{4}$ Molecular Medicine and Medical Biotechnologies, University of Naples "Federico II", Naples, Italy. 'Department of Public Health, University of Naples "Federico II", 
Naples, Italy. ${ }^{6}$ Institute for Mediterranean and Forestal Systems (ISAFOM-CNR), Catania, Italy. ${ }^{7}$ Stazione Zoologica Anton Dohrn, Naples, Italy.

Received: 20 July 2014 Accepted: 24 November 2014 Published: 5 December 2014

\section{References}

1. Wei X, Ai J, Deng Y, Guan X, Johnson DR, Ang CY, Zhang C, Perkins EJ: Identification of biomarkers that distinguish chemical contaminants based on gene expression profiles. BMC Genomics 2014, 15:248.

2. Hamadeh HK, Bushel PR, Jayadev S, Martin K, DiSorbo O, Sieber S, Bennett L, Tennant R, Stoll R, Barrett JC, Blanchard K, Paules RS, Afshari CA: Gene expression analysis reveals chemical-specific profiles. Toxicol Sci 2002, 67(2):219-231

3. Shukla SJ, Huang R, Austin CP, Xia M: The future of toxicity testing: a focus on in vitro methods using a quantitative high-throughput screening platform. Drug Discov Today 2010, 15(23-24):997-1007.

4. Aardema MJ, MacGregor JT: Toxicology and genetic toxicology in the new era of "toxicogenomics": impact of "-omics" technologies. Mutat Res 2002, 499(1):13-25

5. Suter $L$, Babiss $L E$, Wheeldon $E B$ : Toxicogenomics in predictive toxicology in drug development. Chem Biol 2004, 11(2):161-171.

6. Afshari CA, Nuwaysir EF, Barrett JC: Application of complementary DNA microarray technology to carcinogen identification, toxicology, and drug safety evaluation. Cancer Res 1999, 59(19):4759-4760.

7. Hu YF, Kaplow J, He Y: From traditional biomarkers to transcriptome analysis in drug development. Curr Mol Med 2005, 5(1):29-38.

8. Hook SE, Skillman AD, Gopalan B, Small JA, Schultz IR: Gene expression profiles in rainbow trout, Onchorynchus mykiss, exposed to a simple chemical mixture. Toxicol Sci 2008, 102(1):42-60.

9. Hook SE, Skillman AD, Small JA, Schultz IR: Temporal changes in gene expression in rainbow trout exposed to ethynyl estradiol. Comp Biochem Physiol C Toxicol Pharmacol 2007, 145(1):73-85.

10. Zhang Y, Huang K, Deng Y, Zhao Y, Wu B, Xu K, Ren H: Evaluation of the toxic effects of municipal wastewater effluent on mice using omic approaches. Environ Sci Technol 2013, 47(16):9470-9477.

11. Kosmehl T, Otte JC, Yang L, Legradi J, Bluhm K, Zinsmeister C, Keiter SH, Reifferscheid G, Manz W, Braunbeck T, Strähle U, Hollert H: A combined DNA-microarray and mechanism-specific toxicity approach with zebrafish embryos to investigate the pollution of river sediments. Reprod Toxicol 2012, 33(2):245-253.

12. Lettieri T: Recent applications of DNA microarray technology to toxicology and ecotoxicology. Environ Health Perspect 2006, 114(1):4-9.

13. Williams TD, Diab A, Ortega F, Sabine VS, Godfrey RE, Falciani F, Chipman JK, George SG: Transcriptomic responses of European flounder (Platichthys flesus) to model toxicants. Aquat Toxicol 2008, 90(2):83-91.

14. Williams TD, Diab AM, Gubbins M, Collins C, Matejusova I, Kerr R, Chipman JK, Kuiper R, Vethaak AD, George SG: Transcriptomic responses of European flounder (Platichthys flesus) liver to a brominated flame retardant mixture. Aquat Toxicol 2013, 142-143C:45-52.

15. Falciani F, Diab AM, Sabine V, Williams TD, Ortega F, George SG, Chipman JK: Hepatic transcriptomic profiles of European flounder (Platichthys flesus) from field sites and computational approaches to predict site from stress gene responses following exposure to model toxicants. Aquat Toxicol 2008, 90(2):92-101.

16. Williams TD, Davies IM, Wu H, Diab AM, Webster L, Viant MR, Chipman JK, Leaver MJ, George SG, Moffat CF, Robinson CD: Molecular responses of European flounder (Platichthys flesus) chronically exposed to contaminated estuarine sediments. Chemosphere 2014, 108:152-158.

17. Richter CA, Martyniuk CJ, Annis ML, Brumbaugh WG, Chasar LC, Denslow ND, Tillitt DE: Methylmercury-induced changes in gene transcription associated with neuroendocrine disruption in largemouth bass (Micropterus salmoides). Gen Comp Endocrinol 2014, 203:215-224.

18. Williams TD, Turan N, Diab AM, Wu H, Mackenzie C, Bartie KL, Hrydziuszko O, Lyons BP, Stentiford GD, Herbert JM, Abraham JK, Katsiadaki I, Leaver MJ, Taggart JB, George SG, Viant MR, Chipman KJ, Falciani F: Towards a system level understanding of non-model organisms sampled from the environment: a network biology approach. PLoS Comput Biol 2011, 7(8):e1002126.

19. Christiansen HE, Mehinto AC, Yu F, Perry RW, Denslow ND, Maule AG, Mesa MG: Correlation of gene expression and contaminant concentrations in wild largescale suckers: a field-based study. Sci Total Environ 2014, 484:379-389.

20. Baker ME, Vidal-Dorsch DE, Ribecco C, Sprague LJ, Angert M, Lekmine N, Ludka C, Martella A, Ricciardelli E, Bay SM, Gully JR, Kelley KM, Schlenk D, Carnevali O, Šášik R, Hardiman G: Molecular analysis of endocrine disruption in hornyhead turbot at wastewater outfalls in southern california using a second generation multi-species microarray. PLOS One 2013, 8(9):e75553.

21. Xu H, Lam SH, Shen Y, Gong Z: Genome-wide identification of molecular pathways and biomarkers in response to arsenic exposure in zebrafish liver. PLOS One 2013, 8(7):e68737.

22. Antherieu S, Le Guillou D, Coulouarn C, Begriche K, Trak-Smayra V, Martinais S, Porceddu M, Robin MA, Fromenty B: Chronic exposure to low doses of pharmaceuticals disturbs the hepatic expression of circadian genes in lean and obese mice. Toxicol Appl Pharmacol 2014, 276(1):63-72.

23. Iguchi T, Watanabe H, Katsu Y: Application of ecotoxicogenomics for studying endocrine disruption in vertebrates and invertebrates. Environ Health Perspect 2006, 114(Suppl 1):101-105.

24. Mattingly CJ, Rosenstein MC, Colby GT, Forrest JN Jr, Boyer JL: The Comparative Toxicogenomics Database (CTD): a resource for comparative toxicological studies. J Exp Zool A Comp Exp Biol 2006, 305(9):689-692.

25. Hu T, Gibson DP, Carr GJ, Torontali SM, Tiesman JP, Chaney JG, Aardema MJ: Identification of a gene expression profile that discriminates indirect-acting genotoxins from direct-acting genotoxins. Mutat Res 2004, 549(1-2):5-27.

26. Yang L, Kemadjou JR, Zinsmeister C, Bauer M, Legradi J, Muller F, Pankratz M, Jakel J, Strahle U: Transcriptional profiling reveals barcode-like toxicogenomic responses in the zebrafish embryo. Genome Biol 2007, 8(10):R227.

27. Lam SH, Mathavan S, Tong Y, Li H, Karuturi RK, Wu Y, Vega VB, Liu ET, Gong Z: Zebrafish whole-adult-organism chemogenomics for large-scale predictive and discovery chemical biology. PLOS Genet 2008, 4(7):e1000121.

28. Dai YJ, Jia YF, Chen N, Bian WP, Li QK, Ma YB, Chen YL, Pei DS: Zebrafish as a model system to study toxicology. Environ Toxicol Chem 2014, 33(1):11-17.

29. Vrijheid M: Health effects of residence near hazardous waste landfill sites: a review of epidemiologic literature. Environ Health Perspect 2000, 108(Suppl 1):101-112.

30. Palmer SR, Dunstan FD, Fielder H, Fone DL, Higgs G, Senior ML: Risk of congenital anomalies after the opening of landfill sites. Environ Health Perspect 2005, 113(10):1362-1365.

31. Mattiello A, Chiodini P, Bianco E, Forgione N, Flammia I, Gallo C, Pizzuti R, Panico S: Health effects associated with the disposal of solid waste in landfills and incinerators in populations living in surrounding areas: a systematic review. Int J Public Health 2014, 58(5):725-735.

32. Porta D, Milani S, Lazzarino Al, Perucci CA, Forastiere F: Systematic review of epidemiological studies on health effects associated with management of solid waste. Environ Health 2009, 8:60.

33. Makri A, Goveia M, Balbus J, Parkin R: Children's susceptibility to chemicals: a review by developmental stage. J Toxicol Environ Health B Crit Rev 2004, 7(6):417-435.

34. Kishi R, Kobayashi S, Ikeno T, Araki A, Miyashita C, Itoh S, Sasaki S, Okada E, Kashino I, Itoh K, Nakajima S: Ten years of progress in the Hokkaido birth cohort study on environment and children's health: cohort profileupdated 2013. Environ Health Prev Med 2013, 18(6):429-450.

35. Bernard C, Guido P, Colin J, Le Du-Delepierre A: Estimation of the hazard of landfills through toxicity testing of leachates-I: determination of leachate toxicity with a battery of acute tests. Chemosphere 1996, 33(11):2303-2320.

36. Baun A, Ledin A, Reitzel LA, Bjerg PL, Christensen TH: Xenobiotic organic compounds in leachates from ten Danish MSW landfills-chemical analysis and toxicity tests. Water Res 2004, 38(18):3845-3858.

37. Kjeldsen P, Barlaz M, Rooker A, Baun A, Ledin A, Christensen CH: Present and long-term composition of MSW landfill leachate: a review. Crit Rev Environ Sci Technol 2002, 32:297-336.

38. Zhang W, Liu Y, Zhang H, Dai J: Proteomic analysis of male zebrafish livers chronically exposed to perfluorononanoic acid. Environ Int 2012, 42:20-30.

39. Wahlang B, Falkner KC, Gregory B, Ansert D, Young D, Conklin DJ, Bhatnagar A, McClain CJ, Cave M: Polychlorinated biphenyl 153 is a diet-dependent 
obesogen that worsens nonalcoholic fatty liver disease in male C57BL6/J mice. J Nutr Biochem 2013, 24(9):1587-1595.

40. Tan SW, Meiller JC, Mahaffey KR: The endocrine effects of mercury in humans and wildlife. Crit Rev Toxicol 2009, 39(3):228-269.

41. Jaeschke H, McGill MR, Ramachandran A: Oxidant stress, mitochondria, and cell death mechanisms in drug-induced liver injury: lessons learned from acetaminophen hepatotoxicity. Drug Metab Rev 2012, 44(1):88-106.

42. Jian B, Wang D, Chen D, Voss J, Chaudry I, Raju R: Hypoxia-induced alteration of mitochondrial genes in cardiomyocytes: role of Bnip3 and Pdk1. Shock 2010, 34(2):169-175.

43. Pessayre D, Fromenty B, Berson A, Robin MA, Letteron P, Moreau R, Mansouri A: Central role of mitochondria in drug-induced liver injury. Drug Metab Rev 2012, 44(1):34-87.

44. Grattagliano I, Russmann S, Diogo C, Bonfrate L, Oliveira PJ, Wang DQ, Portincasa P: Mitochondria in chronic liver disease. Curr Drug Targets 2011, 12(6):879-893.

45. Sun X, Wang JF, Tseng M, Young LT: Downregulation in components of the mitochondrial electron transport chain in the postmortem frontal cortex of subjects with bipolar disorder. J Psychiatry Neurosci 2006, 31(3):189-196

46. Anitha A, Nakamura K, Thanseem I, Matsuzaki H, Miyachi T, Tsujii M, Iwata Y, Suzuki K, Sugiyama T, Mori N: Downregulation of the expression of mitochondrial electron transport complex genes in autism brains. Brain Pathol 2012, 23(3):294-302.

47. Dahlman I, Forsgren M, Sjogren A, Nordstrom EA, Kaaman M, Naslund E, Attersand A, Arner P: Downregulation of electron transport chain genes in visceral adipose tissue in type 2 diabetes independent of obesity and possibly involving tumor necrosis factor-alpha. Diabetes 2006 55(6):1792-1799.

48. Soronen J, Laurila PP, Naukkarinen J, Surakka I, Ripatti S, Jauhiainen M, Olkkonen VM, Yki-Jarvinen $\mathrm{H}$ : Adipose tissue gene expression analysis reveals changes in inflammatory, mitochondrial respiratory and lipid metabolic pathways in obese insulin-resistant subjects. BMC Med Genomics 2012, 5:9.

49. Olsson AH, Yang BT, Hall E, Taneera J, Salehi A, Nitert MD, Ling C: Decreased expression of genes involved in oxidative phosphorylation in human pancreatic islets from patients with type 2 diabetes. Eur J Endocrinol 2011, 165(4):589-595.

50. Warfel NA, El-Deiry WS: p21WAF1 and tumourigenesis: 20 years after. Curr Opin Oncol 2012, 25(1):52-58

51. Valenti L, Dongiovanni P: CDKN1A: a double-edged sword in fatty liver? Cell Cycle 2014, 13(9):1371-1372.

52. Shin SM, Yang JH, Ki SH: Role of the Nrf2-ARE pathway in liver diseases. Oxid Med Cell Longev 2013, 2013:763257.

53. Rutkowski MJ, Sughrue ME, Kane AJ, Mills SA, Parsa AT: Cancer and the complement cascade. Mol Cancer Res 2010, 8(11):1453-1465.

54. Rensen SS, Slaats Y, Driessen A, Peutz-Kootstra CJ, Nijhuis J, Steffensen R, Greve JW, Buurman WA: Activation of the complement system in human nonalcoholic fatty liver disease. Hepatology 2009, 50(6):1809-1817.

55. Cohen Jl, Roychowdhury S, McMullen MR, Stavitsky AB, Nagy LE: Complement and alcoholic liver disease: role of $\mathrm{C} 1 \mathrm{q}$ in the pathogenesis of ethanol-induced liver injury in mice. Gastroenterology 2010, 139(2):664-674. 674 e661.

56. Barouki R, Gluckman PD, Grandjean P, Hanson M, Heindel JJ: Developmental origins of non-communicable disease: implications for research and public health. Environ Health 2012, 11:42.

57. Paivarinne $H$, Kainulainen $\mathrm{H}$ : DAPIT, a novel protein down-regulated in insulin-sensitive tissues in streptozotocin-induced diabetes. Acta Diabetol 2001, 38(2):83-86.

58. Chen R, Runswick MJ, Carroll J, Fearnley IM, Walker JE: Association of two proteolipids of unknown function with ATP synthase from bovine heart mitochondria. FEBS Lett 2007, 581(17):3145-3148.

59. Ohsakaya S, Fujikawa M, Hisabori T, Yoshida M: Knockdown of DAPIT (diabetes-associated protein in insulin-sensitive tissue) results in loss of ATP synthase in mitochondria. J Biol Chem 2011, 286(23):20292-20296.

60. Krogenaes AK, Ropstad E, Gutleb AC, Hardnes N, Berg V, Dahl E, Fowler PA: In utero exposure to environmentally relevant concentrations of $\mathrm{PCB}$ 153 and PCB 118 disrupts fetal testis development in sheep. J Toxicol Environ Health A 2014, 77(9-11):628-649.
61. Palus J, Rydzynski K, Dziubaltowska E, Wyszynska K, Natarajan AT, Nilsson R: Genotoxic effects of occupational exposure to lead and cadmium. Mutat Res 2003, 540(1):19-28.

62. Yoon K, Kwack SJ, Kim HS, Lee BM: Estrogenic endocrine-disrupting chemicals: molecular mechanisms of actions on putative human diseases. J Toxicol Environ Health B Crit Rev 2014, 17(3):127-174.

63. Ye T, Kang M, Huang Q, Fang C, Chen Y, Shen H, Dong S: Exposure to DEHP and MEHP from hatching to adulthood causes reproductive dysfunction and endocrine disruption in marine medaka (Oryzias melastigma). Aquat Toxicol 2014, 146:115-126.

64. Vested A, Ramlau-Hansen CH, Olsen SF, Bonde JP, Kristensen SL, Halldorsson TI, Becher G, Haug LS, Ernst EH, Toft G: Associations of in utero exposure to perfluorinated alkyl acids with human semen quality and reproductive hormones in adult men. Environ Health Perspect 2013, 121(4):453-458. 458e451-455.

65. Bertoldi K, Spindler C, Dos Santos MF, Vanzella C, Lovatel GA, Elsner VR, Rodrigues MA, Siqueira IR: Effect of landfill leachate on oxidative stress of brain structures and liver from rodents: modulation by photoelectrooxidation process. Ecotoxicol Environ Saf 2012, 84:319-324.

66. Bakare AA, Patel S, Pandey AK, Bajpayee M, Dhawan A: DNA and oxidative damage induced in somatic organs and tissues of mouse by municipal sludge leachate. Toxicol Ind Health 2012, 28(7):614-623.

67. Irizarry RA, Hobbs B, Collin F, Beazer-Barclay YD, Antonellis KJ, Scherf U, Speed TP: Exploration, normalization, and summaries of high density oligonucleotide array probe level data. Biostatistics 2003, 4(2):249-264.

68. Irizarry RA, Ooi SL, Wu Z, Boeke JD: Use of mixture models in a microarray-based screening procedure for detecting differentially represented yeast mutants. Stat Appl Genet Mol Biol 2003, 2:Article1.

69. Huang DW, Sherman BT, Lempicki RA: Systematic and integrative analysis of large gene lists using DAVID Bioinformatics Resources. Nature Protoc 2009, 4(1):44-57.

70. Huang DW, Sherman BT, Lempicki RA: Bionformatics enrichment tools: paths toward the comprehensive fuctional analysis of large gene lists. Nucleic Acids Res 2009, 37(1):1-13.

doi:10.1186/1471-2164-15-1067

Cite this article as: Porreca et al:: Cross-species toxicogenomic analyses and phenotypic anchoring in response to groundwater low-level pollution. BMC Genomics 2014 15:1067.

\section{Submit your next manuscript to BioMed Central and take full advantage of:}

- Convenient online submission

- Thorough peer review

- No space constraints or color figure charges

- Immediate publication on acceptance

- Inclusion in PubMed, CAS, Scopus and Google Scholar

- Research which is freely available for redistribution 